Kamil, I. A., Smith, J. N. \& Williams, R. T. (1953b). Biochem. J. 54, 390.

McGuire, J. S. \& Tomkins, G. M. (1960). J. biol. Chem. 235, 1634.

Miura, S. (1911). Biochem. Z. 36, 25.

Neubauer, O. (1901). Arch. exp. Path. Pharmak. 46, 133.

Ofner, P. (1955). Biochem. J. 61, 287.

Roy, A. B. (1956). Biochem. J. 63, 294.

Sie, H. \& Fishman, W. H. (1957). J. biol. Chem. 225, 453.
Taylor, W. (1954). Biochem. J. 56, 463.

Taylor, W. \& Scratcherd, T. (1961). Biochem. J. 81, 398.

Vestermark, A. \& Boström, H. (1959). Exp. Cell Res. 18, 174.

Vestermark, A. \& Boström, H. (1960). Acta chem. scand.13, 2133.

Wiest, W. G. (1959). Endocrinology, 65, 825.

Wotiz, H. H. \& Lemon, H. M. (1954). J. biol. Chem. 206, 525.

Biochem. J. (1963) 87, 218

\title{
The Biosynthesis of Phenolic Glucosides in Plants
}

\author{
By J. B. PRIDHAM AND MARGARET J. SALTMARSH \\ Department of Chemistry, Royal Holloway College (University of London), Englefield Green, Surrey
}

(Received 12 October 1962)

The first claim that phenolic glucosides were formed when phenols were fed to plants was made by Ciamician \& Ravenna (1916). These workers reported that saligenin (o-hydroxybenzyl alcohol) was converted into salicin (o-hydroxymethylphenyl $\beta$-D-glucopyranoside) by maize seedlings. Other feeding experiments with a variety of phenols have since been carried out and it is now clear that glucosylation of phenols is a common reaction in plant tissues. These studies, leading to the implication of uridine diphosphate glucose in the reaction, have been reviewed by Pridham (1960a). More recent advances have included feeding coumarin and $o$-coumaric acid to white clover with the formation of melilotyl- and $o$-coumaryl-glucosides respectively (Kosuge \& Conn, 1959) and allowing the leaves of various plant species to take up cinnamic acid derivatives (Harborne \& Corner, 1961). In this latter case the corresponding glucose esters were the main products, but with caffeic acid the 3 - and 4- $\beta$-glucosides were also formed. Yamaha \& Cardini $(1960 a)$ have now studied in some detail the enzyme from wheat germ which is specific for the formation of glucosides from uridine diphosphate glucose and phenols with 1,4-dihydroxy groupings (cf. Cardini \& Leloir, 1957; Pridham \& Saltmarsh, 1960) and the enzyme which transfers glucose from uridine diphosphate glucose to arbutin with the formation of a $\beta$-gentiobioside (Yamaha \& Cardini, $1960 b$; cf. Pridham, 1957, 1960b; Anderson, Hough \& Pridham, 1960). The wheat-germ enzyme will also transfer glucose from adenosine diphosphate glucose to quinol (Trivelloni, Recondo \& Cardini, 1962). Marsh (1960) has transferred glucuronic acid from uridine diphosphate glucuronic acid to quercetin using an enzyme from French beans and Barber (1962) has converted this flavonol into the glycoside rutin with an enzyme preparation from mung beans in the presence of uridine diphosphate glucose (or thymidine diphosphate glucose) and thymidine diphosphate rhamnose. The formation of phenolic $\alpha$-glucosides in the absence of nucleotides has been observed with Aspergillus niger extracts, maltose being used as a glucose donor (Pridham, 1961). Acidic derivatives of phenolic glucosides are also produced when broad-bean seeds are treated with simple phenols (Pridham \& Saltmarsh, 1962).

This study has been undertaken to establish the nature of the glucosides formed by feeding simple phenols to the broad bean (Vicia faba) and to compare these products with those obtained from experiments in vitro. All possible steps have been taken to determine accurately the structures of the phenolic glucosides produced, but in some cases low yields or instability of the compounds, or both, have prevented a complete chemical and physical identification. We consider that inadequate characterization may have led to error in some previous publications. For example, some doubt exists about the product of glucosylation of saligenin, where isomeric monoglucosides could be formed by reaction with the phenolic or the primary hydroxyl group.

A preliminary account of this work has been published (Pridham \& Saltmarsh, 1960).

\section{METHODS}

General methods. M.p. values are uncorrected. Ultraviolet-absorption spectra were measured with a Unicam SP.500 spectrophotometer $(1 \mathrm{~cm}$. cell). Free phenolic hydroxyl groups were detected by a bathochromic shift in the presence of base (Mansfield, Swain \& Nordstrom, 1953) and ene-diol groupings were revealed by a hypsochromic shift on subsequent addition of borate ions to the alkaline 
solution (Swain, 1954). Infrared measurements were made with a Unicam SP. 100 double-beam spectrophotometer. In the enzyme-catalysed reactions control incubations with boiled-enzyme preparations were always carried out.

Paper chromatography. Phenolic compounds and sugars were examined on Whatman no. 1 and no. 3 papers respectively by the descending technique. The solvent systems were: $A$, butan-1-ol-ethanol-water (40:11:19, by vol.); $B$, ethyl acetate-acetic acid-water $(9: 2: 2$, by vol.); $C, N N$-dimethylformamide-benzene $(4: 1, \mathrm{v} / \mathrm{v}$; stationary phase), light petroleum (b.p. $60-80^{\circ}$; mobile phase) (Wickberg, 1958); $D, N N$-dimethyl sulphoxide-benzene $(4: 1, \mathrm{v} / \mathrm{v}$; stationary phase), di-isopropyl ether (mobile phase) (Wickberg, 1958). Molybdate-buffered papers were prepared as described by Pridham (1959). The stability of glucosides to oxidation was investigated by spotting these compounds on the starting lines of chromatograms, spraying with an aqueous $\mathrm{M}-\mathrm{FeCl}_{3}$ solution and allowing them to dry at room temperature. These chromatograms were then developed with solvent $A$ and treated with spray $A$.

Paper electrophoresis (see Pridham, 1959). Whatman no. 3 paper was used with the following buffer solutions: $A, 0 \cdot 2 \mathrm{M}$ sodium borate, $\mathrm{pH} 10.0 ; B, 0.05 \mathrm{M}$-glycine, $\mathrm{pH} 10.0 ; C$, 8 mm-ammonium molybdate, $\mathrm{pH} 5 \cdot 2 ; D, 0.2 \mathrm{M}$-sodium acetate, $\mathrm{pH} 5 \cdot 2$.

Location of compounds. Phenolic compounds were detected on paper chromatograms and electrophoretograms by the use of diazotized $p$-nitroaniline- $\mathrm{NaOH}$ (spray $A$; Swain, 1953) and by examination under u.v. light, a Chromatolite (Hanovia Ltd., Slough, Bucks.) being used. $p$-Anisidine hydrochloride (spray $B$; Hough, Jones \& Wadman, 1950) was used for reducing sugars and urea hydrochloride (spray $C$; Isherwood, 1954) for ketoses.

Feeding experiments. Vicia faba (var. Johnson's Longpod) seeds were steeped in water $(24 \mathrm{hr}$.) and then placed between layers of cotton wool soaked in an aqueous solution ( $1 \%$, $\mathrm{w} / \mathrm{v}$ ) of the phenol for 3 days. Treatment of 6 -day-old maize seedlings (Zea mays, var. Golden Harvest) with saligenin was carried out by a similar procedure. With willow (Salix daphnoides), cut ends of shoots were placed in aqueous solutions of saligenin $(1 \%, w / v)$ for $48 \mathrm{hr}$. before examination.

Isolation of phenolic glucosides. The testas were removed from the treated bean seeds and the cotyledons and embryos macerated with aqueous $(90 \%, \mathrm{v} / \mathrm{v})$ methanol. The resulting slurries were centrifuged $(3000 \mathrm{rev} . / \mathrm{min}$. for $15 \mathrm{~min}$. at $5^{\circ}$ ) and the supernatants were then concentrated and examined on paper chromatograms (solvents $A$ and $B$ ) for the presence of phenolic glucosides (u.v. light and spray $A$ ). Maize seedlings and willow shoots were extracted by a similar method. Fractionations of the extracts were achieved on cellulose columns or on Whatman no. 3 paper (solvent $A$ ).

Acidic hydrolysis. The glucosides were heated with $1.5 \mathrm{~N}-\mathrm{HCl}$ at $100^{\circ}$ for $4 \mathrm{hr}$. and the solutions then evaporated to dryness over $\mathrm{NaOH}$ pellets in a vacuum desiccator. The hydrolysates were examined on paper chromatograms with solvents $A$ and $B$ (sprays $A$ and $B$ ).

Enzymic hydrolysis. The glucosides were treated with almond $\beta$-glucosidase (Sigma Chemical Co.; $1 \%$, w/v, in $0.02 \mathrm{M}$-sodium acetate buffer, $\mathrm{pH} \mathrm{5.5)}$ ) at $27^{\circ}$ for $48 \mathrm{hr}$. and the digests then examined chromatographically in the same way as the acidic hydrolyses. Complete hydrolysis of compound $(\mathrm{XV})$ was effected with yeast invertase (British Drug
Houses Ltd. concentrate, $0.2 \mathrm{ml}$.) in $0.1 \mathrm{M}$-sodium phosphate buffer, $\mathrm{pH} 7.5\left(0.2 \mathrm{ml}\right.$.), at $25^{\circ}$ for $30 \mathrm{~min}$.

Methylation of compound (VI). Diazomethane (10 ml.) prepared by Nierenstein's (1930) method was added to freeze-dried (VI) (10 mg.) in dry methanol $(10 \mathrm{ml}$.) and kept at $0^{\circ}$ for $18 \mathrm{hr}$. Acetic acid was then added dropwise until the yellow colour of the solution disappeared. After concentration to dryness the methylated product was heated with methanolic $(7 \%, \mathrm{w} / \mathrm{v}) \mathrm{HCl}$ and evaporated to dryness again over $\mathrm{NaOH}$ pellets in a vacuum desiccator. The hydrolysate was examined on paper chromatograms with solvents $C$ and $D$ and compared with authentic 2,4and 2,5-dimethoxyphenols.

Preparation of 2,5-dimethoxyphenol sulphonate. Conc. $\mathrm{H}_{2} \mathrm{SO}_{4}(3 \mathrm{ml}$.) was added to quinol dimethyl ether $(6 \mathrm{~g}$.$) and$ the mixture heated on an oil bath at $110-120^{\circ}$ for $1 \mathrm{hr}$. The reaction mixture, after cooling, was poured into ice-water and $\mathrm{NaHCO}_{3}$ added to give $\mathrm{pH} 6-7$. The solution was then heated to boiling point and saturated with $\mathrm{NaCl}$ and filtered. On cooling, white crystals of sodium 2,5-dimethoxybenzenesulphonate were obtained The $p$-toluidine derivative had m.p. $203^{\circ}$ [Gallent (1958) found m.p. 202-203 ${ }^{\circ}$ ].

Preparation of 2,5-dimethoxyphenol. Sodium 2,5dimethoxybenzenesulphonate $(6 \mathrm{~g}$.) was fused with $\mathrm{NaOH}$ ( 10 g.) and $\mathrm{KOH} \mathrm{(4} \mathrm{g.)} \mathrm{in} \mathrm{an} \mathrm{iron} \mathrm{crucible.} \mathrm{The} \mathrm{fusion} \mathrm{pro-}$ duct was dissolved in water, the $\mathrm{pH}$ adjusted to 5-6 with conc. $\mathrm{H}_{2} \mathrm{SO}_{4}$ and the solution extracted with ether. Concentration of the ethereal extract gave an oil in low yield. This compound behaved as a typical dimethoxyphenol in solvents $A, C$ and $D$ and gave a blue azo dye with spray $A$.

Separation of compounds (IX) and (X). Initial purification of the mixed glucosides was achieved in thick-paper chromatograms with solvent $A$. The resulting mixed fraction (IX and X) was then resolved by paper electrophoresis with buffer $A$, compound (IX) having $M_{S . A}$ (rate of movement relative to salicylic acid; Pridham, 1959) 0.29 and (X) $M_{S A} 0$. The bands were eluted from the electrophoretograms with water.

o-Hydroxybenzyl $\beta$-glucoside. This was prepared by the method of Anderson et al. (1960).

p-Hydroxy-andm-hydroxy-benzyl $\beta$-glucosides. These were synthesized from glucose and the corresponding phenol by the biochemical method of Bourquelot \& Hérissey (1913).

Wheat-germ enzyme. This was prepared by Yamaha \& Cardini's $(1960 a)$ method and the fraction I obtained by these workers used for the synthesis of glucosides.

Broad-bean enzyme. Dormant bean seeds with testas removed ( $35 \mathrm{~g}$.) were macerated with $0.05 \mathrm{M}$-sodium phosphate buffer, $\mathrm{pH} \mathrm{7.0}\left(105 \mathrm{ml}\right.$.), at $0^{\circ}$. The slurry was left to stand for $2 \mathrm{hr}$. at $5^{\circ}$, centrifuged ( $16000 \mathrm{~g}$ at $0^{\circ}$ for $20 \mathrm{~min}$.) and the supernatant was dialysed against $0.05 \mathrm{M}$-sodium phosphate buffer, $\mathrm{pH} 7 \cdot 0$, at $5^{\circ}$.

Glucose transfer to phenols in vitro. The phenol $(10 \mathrm{mg}$. was incubated with UDP-glucose $(6 \mathrm{mg}$.), enzyme (wheat germ or broad bean; $0.1 \mathrm{ml}$.) and $0.05 \mathrm{M}$-tris-HCl buffer $(0.1 \mathrm{ml}$., $\mathrm{pH} 7.4)$ at $37^{\circ}$ under toluene. The final $\mathrm{pH}$ of the reaction mixture was $7 \cdot 2$. Paper-chromatographic examination (solvents $A$ and $B$ ) was carried out after incubation for $5 \mathrm{hr}$.

Transfer of glucose to phenols was also achieved by incubating (at $\left.37^{\circ}\right)$ wheat-germ enzyme $(0.1 \mathrm{ml}$.) with $0.05 \mathrm{M}$ tris-HCl buffer $(0.1 \mathrm{ml}$., pH 7.4), ATP (2.4 mg.), UTP (1.4 mg.), $\alpha$-D-glucose 1-phosphate $(2.1 \mathrm{mg}$.) and the phenol (1.3 mg.) in the presence of $\mathrm{MgCl}_{2}(0.5 \mathrm{mg}$.) and $\mathrm{NaF}$ 
(2.0 mg.). The reaction mixtures were again examined on paper chromatograms (solvents $A$ and $B$ ) after $5 \mathrm{hr}$. In one experiment $\alpha$-D-glucose 1-phosphate in the above reaction mixture was replaced by $\alpha$-D-galactose 1-phosphate in an attempt to transfer galactose to quinol and resorcinol.

Resorcinol (10 mg.) was also incubated (at $37^{\circ}$ ) separately with $\alpha$-D-glucose 1-phosphate, methyl $\alpha$-D-glucoside, maltose and cellobiose $(6 \mathrm{mg}$. each) in the presence of wheatgerm enzyme $(0 \cdot 1 \mathrm{ml}$.) and $0.05 \mathrm{M}$-tris-HCl buffer $(0 \cdot 1 \mathrm{ml}$., $\mathrm{pH} 7 \cdot 4$ ) and the digests were examined chromatographically (solvents $A$ and $B$ ) after $5 \mathrm{hr}$.

Attempted transfer of glucose to phenols with almond $\beta$-glucosidase. $\beta$-Glucosidase (Sigma Chemical Co.; $0 \cdot 2 \mathrm{ml}$; $1 \%$, w/v, in $0.05 \mathrm{M}$-sodium acetate buffer, $\mathrm{pH} 5 \cdot 6$ ) was incubated separately with arbutin (14 mg.), cellobiose (16 mg.), methyl $\beta$-D-glucoside (10 mg.) and D-glucose $(9 \mathrm{mg}$.) in the presence of quinol, resorcinol or 1,2,4-trihydroxybenzene $\left(1.4 \mathrm{mg}\right.$. each) at $27^{\circ}$. The digests were examined on paper chromatograms after 8, 24 and $72 \mathrm{hr}$. (solvents $A$ and $B$ ).

Attempted transfer of fructose to phenols with yeast invertase. The phenol (10 mg.), sucrose (20 mg.), invertase (British Drug Houses Ltd. concentrate; $0.2 \mathrm{ml}$.) and $0.1 \mathrm{M}$ sodium phosphate buffer, $\mathrm{pH} \mathrm{7.5} \mathrm{(2} \mathrm{ml.),} \mathrm{were} \mathrm{incubated} \mathrm{at}$ $25^{\circ}$ and samples taken and examined chromatographically (solvents $A$ and $B$ ) after $5 \mathrm{~min} ., 3 \mathrm{hr}$. and $20 \mathrm{hr}$.; a high pH was chosen in the hope that increased ionization of the phenolic hydroxyl groups would facilitate the transfer reaction. Only with saligenin was a glycosylated product (XV) obtained and this was isolated from the reaction mixture by chromatography on thick paper (solvent $A$ ). The hydrolysis products obtained on heating (XV) with $0.01 \mathrm{~N}-\mathrm{H}_{2} \mathrm{SO}_{4}$ at $100^{\circ}$ for $10 \mathrm{~min}$. were examined on paper chromatograms (solvents $A$ and $B$ ).

\section{RESULTS}

\section{Feeding experiments}

Preliminary experiments showed that broadbean seeds that had been allowed to germinate for $24 \mathrm{hr}$. before feeding with phenols gave the highest yields of glucosides, in comparison with organs of the mature plant. In addition, seed extracts contained fewer interfering phenolic substances than extracts of the green parts of the plant and this facilitated the isolation of the glucosylated products. The main properties of the glucosides formed in the feeding experiments are summarized in Table 1. Quinol gave a higher yield of the corresponding monoglucoside, arbutin (I; $300 \mathrm{mg}$. from $110 \mathrm{~g}$. dry wt. of seeds) than any other phenol that was used for feeding. Arbutin, unlike the other glucosides, was obtained in a crystalline form from water: m.p. and mixed m.p. $199^{\circ},[\alpha]_{\mathrm{D}}^{17}-62^{\circ}$ (c 1.8 in water) (Found: $\mathrm{C}, 49 \cdot 7 ; \mathrm{H}, 6.3$. Calc. for $\mathrm{C}_{12} \mathrm{H}_{16} \mathrm{O}_{7}, \mathrm{H}_{2} \mathrm{O}: \mathrm{C}, 49 \cdot 7 ; \mathrm{H}, 6 \cdot 2 \%$ ), and was also characterized by paper chromatography and electrophoresis against authentic arbutin and by comparative u.v. and i.r. spectrophotometry. The penta-acetate of $(\mathrm{I})$ had m.p. and mixed m.p. 146.5 (Found: $\mathrm{C}, 54 \cdot 3 ; \mathrm{H}, 5 \cdot 6$. Calc. for $\mathrm{C}_{22} \mathrm{H}_{26} \mathrm{O}_{12}: \mathrm{C}$,
$54 \cdot 8 ; \mathrm{H}, 5 \cdot 4 \%)$. The i.r. spectrum of the pentaacetate was identical with that of authentic $p$-hydroxyphenyl $\beta$-D-glucopyranoside penta-acetate. The unequivocal identification of (I) supports the structures proposed for the other glucosides, which could only be examined by less rigorous methods.

The mono $\beta$-glucoside (II), obtained by feeding with resorcinol, was isolated as a freeze-dried powder and had paper-chromatographic and electrophoresis properties identical with those of authentic $m$ hydroxyphenyl $\beta$-glucoside.

Similarly, compound (III), which was derived from catechol, was electrophoretically and chromatographically indistinguishable from $o$-hydroxyphenyl $\beta$-glucoside.

Two mono $\beta$-glucosides, compounds (IV) and (V), in the approximate proportions of 3:1 (as judged visually from paper chromatograms) were produced in low yields by seeds fed with pyrogallol. Compound (IV) gave a red-brown colour on molybdatetreated paper chromatograms and on molybdate electrophoretograms (buffer $C$ ). This reaction, in conjunction with the $R_{F}$ and $M_{S A}$ values (Table 1) is highly characteristic of compounds containing an ene-diol grouping (Pridham, 1959). The spectrum of (IV) is also characteristic of an ene-diol and the structure of this compound must therefore be 2,3dihydroxyphenyl $\beta$-glucoside. Compound (V) gave negative ene-diol reactions and is presumably 2,6 dihydroxyphenyl $\beta$-glucoside.

Extracts prepared after feeding 1,2,4-trihydroxybenzene to bean seeds contained three compounds, (VI), (VII) and (VIII), in the approximate proportions of $6: 2: 1$; which behaved as monoglucosides on paper chromatograms and electrophoretograms. Insufficient amounts of (VIII) could be obtained for hydrolysis studies and this compound seemed to be much more unstable than (VI) or (VII). Compound (VII) behaved as an ene-diol in the presence of molybdate ions, unlike compound (VI). Attempts to detect the ene-diol grouping in (VII) by spectrophotometry failed owing to the instability of the compound. Treatment of all three glucosides with dilute aqueous ferric chloride solution showed that only (VI) was not oxidized, and therefore presumably did not possess a potential quinonoid structure. Methylation followed by hydrolysis of (VI) yielded a compound that co-chromatographed with 2,4-dimethoxyphenol and gave an azo dye of the same colour with spray $A$. This methylated phenol could be easily distinguished from 2,5dimethoxyphenol by the use of 'two organic-phase' chromatography (solvents $C$ and $D$ ). The evidence strongly suggests that compounds (VI) and (VII) are 2,4- and 3,4-dihydroxyphenyl $\beta$-glucosides respectively. Compound (VIII) may well be the 2,5 isomer. 


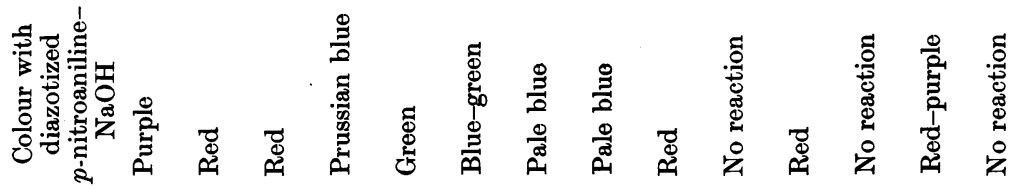

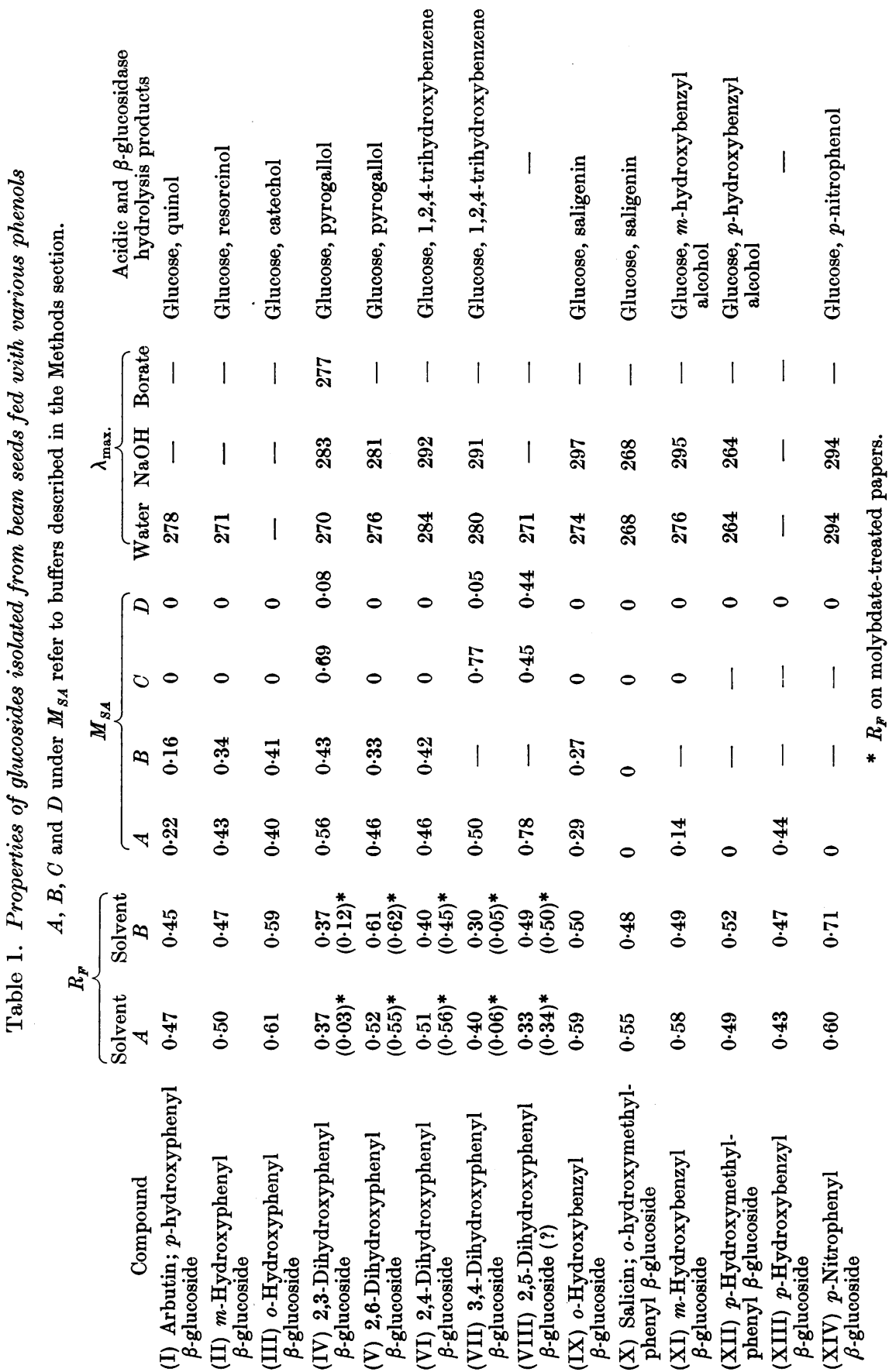


$o$-Hydroxybenzyl $\beta$-glucoside (IX) was the main product formed on feeding saligenin to germinating beans. Compound (IX) and authentic o-hydroxybenzyl $\beta$-glucoside (Anderson et al. 1960) behaved identically on paper chromatograms and electrophoretograms and gave the same red coloration with the diazonium spray reagent $(A)$. A trace of salicin (X) was also detected as a u.v.-absorbing spot on a paper electrophoretogram (buffer $A$ ) of the seed extract. Failure of compound $(\mathrm{X})$ to react with spray $A$ indicated the absence of a free phenolic hydroxyl group, as did u.v. spectrophotometry, which on the other hand showed the presence of a free phenolic hydroxyl group in the major product (IX) (cf. Rabaté \& Ramart-Lucas, 1935). The electrophoresis and chromatographic behaviour of compound $(\mathrm{X})$ was identical with that of authentic salicin. $o$-Hydroxybenzyl $\beta$-glucoside was also the major glucoside formed when willow shoots and maize seedlings were allowed to take up saligenin. In the latter case no salicin was detected; with the willow, salicin was present but was, of course, also found in the control shoots.

$m$-Hydroxybenzyl alcohol was likewise converted into the corresponding alcoholic glucoside $(\mathrm{m}$ hydroxybenzyl $\beta$-glucoside, XI) by the bean. No definite evidence was obtained for the presence of the isomeric phenolic glucoside in the seed extracts. The glucoside obtained by incubating $m$-hydroxybenzyl alcohol with excess of $D$-glucose and $\beta$ glucosidase (Bourquelot \& Hérissey, 1913) gave the same colour with spray reagent $A$ and had identical chromatographic, electrophoresis and spectral properties with compound (XI). Hydrolysis of both compounds gave glucose and $m$-hydroxybenzyl alcohol.

In contrast, $p$-hydroxybenzyl alcohol was converted largely into $p$-hydroxymethylphenyl $\beta$ glucoside (XII). The absence of a free phenolic hydroxyl group in this compound was evident from electrophoresis and spectrophotometric studies. A small amount of a compound (XIII) that gave a pink-purple colour with spray $A$ also accompanied (XII). Insufficient quantities of (XIII) were present for detailed studies but it behaved in an identical manner with the glucoside obtained from $p$-hydroxybenzyl alcohol (by Bourquelot \& Hérissey's, 1913, method) on paper chromatograms and electrophoretograms. The synthetic compound had $\lambda_{\max } 279 \mathrm{~m} \mu$ shifting to $290 \mathrm{~m} \mu$ on addition of alkali, and on hydrolysis with acid and $\beta$-glucosidase yielded glucose and $p$-hydroxybenzyl alcohol. It is therefore assumed that this glucoside and compound (XIII) are $p$-hydroxybenzyl $\beta$-glucoside.

A compound (XIV) with $\lambda_{\max .} 294 \mathrm{~m} \mu$ was found in extracts of beans that had been fed with $p$-nitrophenol. The compound was electrophoretically immobile with all the buffers used, and could be detected on paper with a spray reagent for nitro compounds (Maddy, 1959). This evidence, together with hydrolysis studies, suggests that (XIV) is $p$-nitrophenyl $\beta$-glucoside. 2,4-Dinitrophenol-treated seeds did not produce detectable glucosides.

\section{Glucosylation by wheat-germ and bean enzymes with uridine diphosphate glucose and other donors}

A wheat-germ enzyme (cf. Yamaha \& Cardini, $1960 a$ ) with UDP-glucose produced the corresponding mono $\beta$-glucosides when incubated with quinol, resorcinol and catechol. With saligenin, and $m$ hydroxybenzyl alcohol, only the alcoholic groups were glucosylated, giving $o$-hydroxy-(IX) and $m$ hydroxy-(XI)-benzyl $\beta$-glucoside. No glucoside formation could be detected with $p$-hydroxybenzyl alcohol. Pyrogallol gave one glucoside that was identical with 2,3-dihydroxyphenyl $\beta$-glucoside (IV); 2,4-dihydroxyphenyl $\beta$-glucoside (VI) was the only compound obtained from 1,2,4-trihydroxybenzene. When UDP-glucose was replaced by potential glucose donors such as $\alpha$-D-glucose 1-phosphate, maltose, cellobiose or methyl $\alpha$-D-glucoside, glucose transfer could not be demonstrated with resorcinol as an acceptor. When ATP, UTP and $\alpha$-D-glucose 1-phosphate were used to replace UDPglucose, however, mono- $\beta$-glucoside formation was observed with quinol, resorcinol, catechol and saligenin as acceptor substrates. (With the last-named, $o$ hydroxybenzyl $\beta$-glucoside, IX, was again formed.) Attempts to synthesize phenolic galactosides by replacing $\alpha$-D-glucose 1-phosphate by $\alpha$-D-galactose 1-phosphate failed. A phosphate buffer extract of dormant broad-bean seeds also glucosylated quinol, resorcinol, catechol and saligenin in the presence of UDP-glucose, giving the same products as the wheat-germ enzyme. This preparation was, however, less active than the wheat-germ enzyme.

\section{Experiments with emulsin and invertase}

Incubation of quinol, resorcinol and 1,2,4-trihydroxybenzene with cellobiose, arbutin, methyl $\beta$-D-glucoside or high concentrations of $\mathrm{D}$-glucose in the presence of $\beta$-glucosidase (cf. Bourquelot \& Hérissey, 1913) did not produce glucosides, and fructose could not be transferred from sucrose to quinol or 1,2,4-trihydroxybenzene by yeast invertase. This latter enzyme did, however, produce a fructoside $(\mathrm{XV})$ with saligenin, which gave a pink colour with the diazonium spray $A$, thus indicating the presence of a free phenolic hydroxyl group. This was supported by the spectrum, $\lambda_{\max .} 274 \mathrm{~m} \mu$, changing to $291 \mathrm{~m} \mu$ with alkali. The compound could also be located on chromatograms as a blue spot $\left[R_{F} 0.68\right.$ in solvent $A$, cf. compound (IX), Table 1] with urea hydrochloride, a specific reagent 
for ketoses, and on hydrolysis with yeast invertase it yielded saligenin and fructose (the compound was not hydrolysed by $\beta$-glucosidase). These hydrolysis products were also rapidly released when (XV) was heated with $0.01 \mathrm{~N}$-sulphuric acid (o-hydroxybenzyl $\beta$-glucoside is stable under these conditions). This evidence strongly suggests that $(\mathrm{XV})$ is $o$-hydroxybenzyl $\beta$-fructofuranoside.

\section{DISCUSSION}

This study has shown that the major primary products formed by feeding broad-bean seeds with mono-, di- and tri-hydric phenols are the corresponding mono- $\beta$-glucosides. The formation of oligoglucosides or glucosylation of more than one hydroxyl group cannot be altogether excluded in view of the difficulty in detecting small amounts of these higher-molecular-weight compounds in the complex extracts.

With enzyme preparations from wheat-germ and broad-bean seeds with UDP-glucose as the glucose donor, phenols were also glucosylated in vitro and the resulting products closely resembled those obtained from the experiments in vivo. The reaction with the di- and tri-hydric phenols in vitro did, however, appear to be more specific and only one isomer in each case resulted, this corresponding to the major component produced in the feeding experiments. Glucosylation of phenols has also been achieved with UTP, $\alpha$-D-glucose 1-phosphate and a wheat-germ extract, i.e. utilizing the UDP-glucosepyrophosphorylase of the germ. Attempts to synthesize phenolic glucosides by simple transferase reactions involving almond $\beta$-glucosidase and 'low energy'-potential glucose donors failed. Similar unsuccessful experiments have been recorded in the past with glucose-containing disaccharides, aryland alkyl-glucosides and glucose as donors (Cardini \& Yamaha, 1958; Pridham, 1960b; Anderson et al. 1960). Such systems will, of course, glucosylate aromatic and aliphatic alcohols (Rabaté, 1935; Anderson et al. 1960; Dedonder, 1961; Jermyn, 1961). Fructosylation of phenolic hydroxyl groups also could not be effected with sucrose and yeast invertase although here again this enzyme readily transfers fructose to other sugar molecules and to simple aliphatic alcohols (Edelman, 1956; Dedonder, 1961) and now, as we have shown, to saligenin, forming $o$-hydroxybenzyl $\beta$-fructofuranoside.

UDP-glucose occurs widely in plant tissues (Ginsburg, Stumpf \& Hassid, 1956; Rowan, 1959; Ziegler, 1960; Dutton, Carruthers \& Oldfield, 1961), and Abdel-Wahab \& El-Kinawi (1959, 1960) have presented evidence which suggests that it occurs in Vicia faba. We also have chromatographic evidence for the existence of this nucleotide in the broad bean. It is probable therefore that UDP. glucose is a donor molecule for the glucosylation of phenols in the bean, and indeed in all higher plant tissues although other nucleotide derivatives, such as thymidine diphosphate glucose (Barber, 1962), may also be involved in this reaction.

Many different types of phenols can be glucosylated by plant tissues. This may be due to the presence in the cells of a number of different enzymes (or different active sites on one enzyme) with relatively high acceptor specificities or to a single enzyme of low specificity. The former hypothesis at present seems more likely in view of the isolation from wheat germ of an enzyme which is specific for the glucosylation of phenols with 1,4-dihydroxy groupings. Crude wheat-germ extracts with UDPglucose will glucosylate phenols with other hydroxyl arrangements (Yamaha \& Cardini, 1960a). A multienzyme system in which the components have different activities could also account for the different amounts of the isomeric monoglucosides produced on feeding di- and tri-hydric phenols and phenolic alcohols to bean seeds. With a single enzyme these results might be explained by stereospecificity or by the relative chemical reactivity of hydroxyl groups in the polyhydric compound. Hydroxyl reactivity and stereospecificity would presumably also play important roles with a multienzyme system. Preliminary feeding experiments with pyrogallol, saligenin and $p$-hydroxybenzyl alcohol first led us to believe that the most strongly dissociated hydroxyl group was most readily glucosylated but this theory became unsatisfactory when a number of other phenols were tested in vivo and in vitro. (With saligenin, hydrogen-bond formation between the hydrogen of the phenolic hydroxyl group and the alcoholic oxygen atom strongly activates the alcohol group, and one would expect this on purely chemical grounds to be readily glucosylated, as was the case.)

It should also be remembered that results from feeding experiments and experiments with crude enzymes in vitro could be misleading owing to the instability of the phenolic glucosides to other enzyme systems such as the hydrolases and phenol oxidases.

It is of interest to consider the biosynthesis of salicin as our results suggest that saligenin is not the precursor. Ciamician \& Ravenna (1916) claimed that salicin was formed by maize seedlings that had been treated with saligenin. Our own experiments with maize and Salix daphnoides strongly suggest that $o$-hydroxybenzyl $\beta$-glucoside is the major product formed from saligenin. With maize, no salicin could be detected. Salicin occurs naturally in Salix daphnoides, but here no marked increase was observed. These differences in results may be due to the fact that Ciamician \& Ravenna (1916) 
used a method that did not clearly distinguish between the two isomeric glucosides of saligenin. According to Yamaha \& Cardini $(1960 a)$ wheatgerm extracts incubated with UDP-glucose and saligenin produce a compound with similar chromatographic properties to salicin. Here again our own experiments with wheat-germ and broad-bean enzymes showed clearly that the major product is the isomeric glucoside and that little, if any, salicin is produced. It is possible therefore that in vivo saligenin is not the precursor of salicin, always assuming that our feeding experiments allowed the phenol to reach the correct site for salicin synthesis in the plant. Ibrahim \& Towers (1959) suggest that salicylic acid may be a common metabolite of plants, and Klämbt (1962) has shown that benzoic acid can be converted into salicylic acid and salicylic acid $\beta$-glucoside by several species of plants. It is conceivable therefore that salicin biosynthesis proceeds via the corresponding glucoside followed by reduction of the carboxyl group to a primary alcohol group. In this connexion, it can be noted that helicin (o-formylphenyl $\beta$-D-glucoside), gaultherin (o-carboxymethylphenyl 6-O- $\beta$-D-xylosyl- $\beta$ $D$-glucoside) and violutin (o-carboxymethylphenyl 6- $O$ - $\beta$-L-arabinosyl- $\beta$-D-glucoside) occur naturally in plants (McIlroy, 1951); a glycoside of salicylic acid has so far not been found, however.

\section{SUMMARY}

1. The structures of the mono $\beta$-glucosides formed by germinating broad-bean seeds in the presence of various phenols have been studied.

2. Enzyme preparations from wheat-germ and broad-bean seeds will glucosylate phenolic and alcoholic hydroxyl groups in the presence of uridine diphosphate glucose (or for wheat-germ enzyme, with uridine triphosphate and $\alpha$-D-glucose 1phosphate). The products obtained with these enzymes closely resemble those produced in the experiments in vivo.

3. The nature of the phenol-glucosylating system in plants is considered.

4. Saligenin in vivo and in vitro mainly gives rise to $o$-hydroxybenzyl $\beta$-glucoside, and not salicin. The biosynthesis of this latter compound is discussed.

We are greatly indebted to Spillers Ltd. for a generous gift of wheat germ and to Professor E. Adler for specimens of methylated phenols. The paper-electrophoresis apparatus was built with the aid of a grant from The Royal Society. Professor E. J. Bourne is thanked for his interest and encouragement and M.J.S. acknowledges the receipt of a postgraduate studentship from the Department of Scientific and Industrial Research.

\section{REFERENCES}

Abdel-Wahab, M. F. \& El-Kinawi, S. A. (1959). Acta chem. scand. 13, 1653.

Abdel-Wahab, M. F. \& El-Kinawi, S. A. (1960). Acta chem. scand. 14, 1667.

Anderson, J. D., Hough, L. \& Pridham, J. B. (1960). Biochem. J. 77, 564.

Barber, G. A. (1962). Biochemistry, 1, 463.

Bourquelot, E. \& Hérissey, H. (1913). C.R. Acad. Sci., Paris, 156, 1790.

Cardini, C. E. \& Leloir, L. F. (1957). Cienc. e Invest. 13, 514.

Cardini, C. E. \& Yamaha, T.(1958). Nature, Lond., 182, 1446.

Ciamician, G. L. \& Ravenna, C. (1916). R.C. Accad. Lincei, $18,419$.

Dedonder, R. A. (1961). Annu. Rev. Biochem. 30, 347.

Dutton, J. V., Carruthers, A. \& Oldfield, J. F. T. (1961). Biochem. J. 81, 266.

Edelman, J. (1956). Advanc. Enzymol. 17, 189.

Gallent, J. B. (1958). J. org. Chem. 23, 75.

Ginsburg, V., Stumpf, P. K. \& Hassid, W. Z. (1956). J. biol. Chem. 223, 977.

Harborne, J. B. \& Corner, J. J. (1961). Biochem. J. 81, 242.

Hough, L., Jones, J. K. N. \& Wadman, W. H. (1950). J. chem. Soc. p. 1702.

Ibrahim, R. K. \& Towers, G. H. N. (1959). Nature, Lond., $184,1803$.

Isherwood, F. A. (1954). Brit. med. Bull. 10, 202.

Jermyn, M. A. (1961). Rev. pure appl. Chem. 11, 92.

Klämbt, H. D. (1962). Nature, Lond., 196, 491.

Kosuge, T. \& Conn, E. E. (1959). J. biol. Chem. 234, 2133.

McIlroy, R. J. (1951). The Plant Glycosides, p. 15. London: Edward Arnold and Co.

Maddy, A. H. (1959). Nature, Lond., 184, 1397.

Mansfield, G. H., Swain, T. \& Nordstrom, C. G. (1953). Nature, Lond., 172, 23.

Marsh, C. A. (1960). Biochim. biophys. Acta, 44, 359.

Nierenstein, M. (1930). J. Amer. chem. Soc. 52, 4012.

Pridham, J. B. (1957). Analyt. Chem. 29, 1167.

Pridham, J. B. (1959). J. Chromat. 2, 605.

Pridham, J. B. (1960a). In Phenolics in Plants in Health and Disease, p. 9. Ed. by Pridham, J. B. London: Pergamon Press Ltd.

Pridham, J. B. (1960b). Biochem. J. 76, 13.

Pridham, J. B. (1961). Chem. \& Ind. p. 1172.

Pridham, J. B. \& Saltmarsh, M. J.(1960). Biochem.J.74,42P.

Pridham, J. B. \& Saltmarsh, M.J.(1962). Biochem.J.82, 44 P.

Rabaté, J. (1935). Bull. Soc. Chim. biol., Paris, 17, 572.

Rabaté, J. \& Ramart-Lucas, P. (1935). Bull. Soc. chim. Fr. 2, 1596.

Rowan, K. S. (1959). Biochim. biophys. Acta, 34, 270.

Swain, T. (1953). Biochem. J. 53, 200.

Swain, T. (1954). Chem. \& Ind. p. 1480.

Trivelloni, J. C., Recondo, E. \& Cardini, C. E. (1962). Nature, Lond., 195, 1202.

Wickberg, B. (1958). Acta chem. scand. 12, 615.

Yamaha, T. \& Cardini, C. E. (1960a). Arch. Biochem. Biophys. 86, 127.

Yamaha, T. \& Cardini, C. E. (1960b). Arch. Biochem. Biophys. 86, 133.

Ziegler, H. (1960). Naturwissenschaften, 47, 140. 